\title{
The G20's Role in Fulfilling the UN 2030 Agenda
}

Zhang Chun

\begin{abstract}
Thanks to their huge potential and effective toolkit, the Group of Twenty (G20) countries have exhibited strong resolve to implement the United Nations 2030 Agenda for Sustainable Development (UN 2030 Agenda). Their joint endeavor will, in turn, facilitate the transition of the G20 from an ad hoc mechanism to a long-term institution for sustainable development. With regard to the remaining gap of political willingness among countries and the absence of behavioral rules in implementing the Agenda, the coordinating authority of the G20 should be strengthened and the existing institutions reformed. Specific measures must be taken, which include: (a) strengthening the coordinating capability of the Development Working Group under the G20 (G20-DWG); (b) making the G20 an example for the rest of the world in realizing the Agenda; (c) calling for an upgraded version of the common but differentiated responsibility (CBDR) principle; (d) strengthening coordination with related organizations for the follow-up and review mechanisms of the Agenda; (e) enhancing public awareness of those post-MDG targets and lost-targets to strengthen the central role of the G20 in implementing the Agenda; and (f) making the
\end{abstract}

Zhang Chun is Deputy Director of the Institute of Foreign Policy Studies, Shanghai Institutes for International Studies. He is also Deputy Editor-in-Chief of the China Quarterly of International Strategic Studies. His mailing address is: 195-15 Tianlin Road, Shanghai 200233, China. He can also be reached at zhangchunster@163.com.

(C) 2016 World Century Publishing Corporation and Shanghai Institutes for International Studies China Quarterly of International Strategic Studies, Vol. 2, No. 3, 311-326

DOI: $10.1142 / S 2377740016500238$ 
G20 a long-term leader in supporting development rights of the developing world.

Keywords: Group of Twenty (G20); UN 2030 Agenda; common but differentiated responsibilities (CBDR); global partnership.

In the Leaders' Communique reached at the Antalya Summit in November 2015, Group of Twenty (G20) leaders stated that "the [UN] 2030 Agenda, including the Sustainable Development Goals (SDGs) and the Addis Ababa Action Agenda, sets a transformative, universal and ambitious framework for global development efforts." They further pledged to "ensure that no one is left behind in our efforts to eradicate poverty and build an inclusive and sustainable future for all...We will develop an action plan in 2016 to further align our work with the 2030 Agenda." ${ }^{1}$ To accomplish these goals requires close communication among G20 members to bridge their gaps in implementing the UN 2030 Agenda for Sustainable Development (hereinafter "UN 2030 Agenda"). This critical bridge, however, is absent in both G20 institutions and the implementation mechanisms of the Agenda. In this light, functions of the Development Working Group (DWG) under the G20 framework need to be strengthened and expanded, in order to coordinate development efforts within the G20 and further integrate the G20's endeavors to realize the UN 2030 Agenda.

\section{The UN 2030 Agenda: Achievements and Shortcomings}

Setting forth more universal, open, and demanding goals, the UN 2030 Agenda is an extension and upgrade of the UN Millennium Development Goals (MDGs). The High-level Plenary Meeting of the 65th Session of the UN General Assembly on the MDGs convened in September 2010 officially initiated the discussion about a post-2015 development agenda, which has undergone three phases since then.

The first phase, from September 2010 to August 2013, witnessed worldwide consultation and discussion among all UN members, the focus

${ }^{1}$ The G20, G20 Leaders' Communiqué, Antalya Summit, November 15-16, 2015, http:// g20.org.tr/g20-leaders-commenced-the-antalya-summit/. 
of which was to take stock of the post-MDGs and to seek international legitimacy for the new agenda. During the second phase, from September 2013 to August 2014, the Open Working Group of the General Assembly on Sustainable Development Goals (OWG) led the shift of discussion to linking the MDGs with the SDGs, so as to make a new "post-2015 Development Agenda," whose official name became the "UN 2030 Agenda" in midAugust 2015. Based on earlier documents, especially the proposal of the OWG, discussion and negotiation of the third phase, from September 2014 to September 2015, focused on how to finalize the outcome document to be adopted at the UN Sustainable Development Summit in September $2015 .{ }^{2}$ In the meantime, specific indicators for evaluating the implementation were developed in March 2016, under the guidance of the Inter-Agency and Expert Group on Sustainable Development Goals (IAEG-SDGs).

As of March 2016, the UN 2030 Agenda has had 17 goals, 169 targets, and about 230 indicators. ${ }^{3}$ The 17 SDGs can be categorized into four types according to their different foci: Goals 1 to 7 call for ending poverty and hunger, ensuring education, achieving gender equality, and ensuring access to water, sanitation and energy, with a focus on human rights and personal development, especially the basic rights of underprivileged groups; Goals 8 to 11 emphasize sustainable economic growth and inclusive society, including facilitating long-term employment, urbanization and human settlements, industrialization and innovation, consumption and production, and reducing inequality; Goals 13 to 15 aim at environmental sustainability, including combating climate change, conserving marine resources, and protecting territorial ecosystem; Goals 16 and 17 focus on implementation of the other goals through international cooperation by enhancing institution building, strengthening the means of implementation (MOIs), and revitalizing the Global Partnership.

The 17 SDGs can also be divided into three groups according to their connections with the MDGs. The first group is about pursuing unfinished business of the MDGs, including ending poverty, promoting education and

2Zhang Chun, “Post-2015 Development Agenda and China's Potential Contribution," UN Studies, No. 1 (2014), p. 71-80.

${ }^{3}$ The United Nations, Transforming Our World: The 2030 Agenda for Sustainable Development, A/RES/70/1, October 25, 2015 All quotations on the SDGs are from this document, if not otherwise indicated. 
sanitation, and so on-mainly Goals 1 to 6. Naturally, the UN 2030 Agenda has upgraded every unfinished MDG and raised the standards. The second group includes new goals on inclusive development, climate change, sustainable consumption and production, marine conservation, ecosystem protection, and peaceful and inclusive society. The third group is about MOIs and the Global Partnership. For example, Goal 17 is to "strengthen the means of implementation and revitalize the Global Partnership for Sustainable Development," with 19 targets for building the Global Partnership. Goals 1 to 16 also include 43 means of implementation. In other words, there are 62 targets in the UN 2030 Agenda that address the MOIs and the Global Partnership.

As UN Under-Secretary-General Wu Hongbo put it, the UN 2030 Agenda boasts four unique characteristics: expanding participation in agenda-setting, universal application, updated development conception, and greater emphasis on implementation. ${ }^{4}$ Nonetheless, the Agenda also has obvious shortcomings: above all, despite its emphasis on the unfinished business of the MDGs, the Agenda

Ambitious as it is, the UN 2030 Agenda will be difficult to achieve without a strong and lasting leadership. fails to fully address the issue - of the total 169 targets, fewer than ten are set to continue achieving the MDGs, while almost 100 are for the new SDGs. Furthermore, the Agenda's emphasis on policy coherence, data revolution, and global comparability of data reveals that the controversial issue of conditionality for aid has made its way into the Agenda, making the Agenda a more or less legally binding document, and thus likely to incur resistance from some countries. Finally, although the Agenda stresses universality, the North-South divide remains evident. For example, throughout the target framework, "developed countries" are mentioned about 20 times, while "developing countries" and "least developed countries" are mentioned over 100 times.

Composed of all the major economies, especially the most developed countries in the world, the G20 can employ its policy toolkit to play a leading role in implementing the UN 2030 Agenda, which will not only

4"Sustainable Development Goals of Profound Historic Significance," People's Daily Online, September 23, 2015, http://en.people.cn/n/2015/0923/c90000-8954198.html. 
facilitate its own transformation from an ad hoc crisis management mechanism to a long-term global governance institution, but also promote the achievement of sustainable development itself. In view of the abovementioned shortcomings of the UN 2030 Agenda, the G20 should also step up its efforts in MDGs-related areas and try to build a Global Partnership for sustainable development. In particular, the G20 should push forward the implementation of "Goals for the rich," 5 so as to make due contribution to poverty reduction and realizing the wish that "no one is left behind."

\section{Prospects for Implementing the UN 2030 Agenda}

The UN 2030 Agenda is expected to guide global development efforts and cooperation in the next 15 years. As a gradual process, its implementation needs continuous adjustment in practice. Basically, the implementation of the Agenda includes four elements: aligning national and regional strategies and policy planning, aligning and adjusting national and regional indicators, building follow-up and review mechanisms, and forging a Global Partnership.

The alignment of national and regional strategies and policy planning is the key to implementing the UN 2030 Agenda. Despite its non-legally binding nature, the Agenda is one for global development. Thus countries around the world need to adjust their targets based on their own circumstances. As the UN document points out,

[T]he Sustainable Development Goals and targets are integrated and indivisible, global in nature and universally applicable, taking into account different national realities, capacities and levels of development and respecting national policies and priorities. Targets are defined as aspirational and global, with each Government setting its own national targets guided by the global level of ambition but taking into account national circumstances. Each Government will also decide how these aspirational and

\footnotetext{
${ }^{5}$ Barbara Adams and Karen Judd, “2030 Agenda and the SDGs: Indicator Framework, Monitoring and Reporting," Global Policy Watch, March 18, 2016, https://www.globalpolicywatch.org/blog/2016/03/18/2030-agenda-sdgs-indicator/.
} 
global targets should be incorporated into national planning processes, policies and strategies. ${ }^{6}$

In other words, the first crucial step for countries and regions is to align their respective policy priorities, action plans, and budgets with the GoalTarget-Indicator (GTI) framework in the UN 2030 Agenda, which will not only facilitate the implementation of the Agenda, but also ensure that countries can steer themselves in the right direction of development.

If the alignment of strategies and policy planning reflects the political willingness of countries, the alignment and adjustment of indicators reflects the implementation of the UN 2030 Agenda itself. During the translation of Goals/targets into indicators, many targets are replaced or lost, and many indicators fail to reflect the true intentions of corresponding Goals/targets. For example, Target 1.a requires all countries to "ensure significant mobilization of resources from a variety of sources....in order to provide adequate and predictable means for developing countries, in particular least developed countries, to implement programs and policies to end poverty in all its dimensions," emphasizing "development cooperation," but the two corresponding indicators have made no mention of this issue. ${ }^{7}$ Another example is that the indicator framework lacks indicators for developed countries or "the rich," which should have included how developed countries can help developing countries achieve the SDGs, what the SDGs they should achieve, and how to incorporate Goals for the rich and for the poor into one indicator framework. ${ }^{8}$

Thus, although the alignment of strategies and policy planning may reflect the political willingness of countries to implement the UN 2030 Agenda, if different countries over-adjust the indicators, serious distortions

${ }^{6}$ The United Nations, Transforming Our World: The 2030 Agenda for Sustainable Development, p. 14.

${ }^{7}$ Indicator 1.a.1 is about "Percentage of resources allocated by the government directly to poverty reduction programs"; Indicator 1.a.2 is about "Spending on essential services (education, health and social protection) as a percentage of total government spending". Although some portion of government spending may come from development cooperation, these two indicators do not reflect cooperation itself. See Report of the Inter-agency and Expert Group on Sustainable Development Goal Indicators (Revised) (E/CN.3/2016/2/Rev.1), Annex III.

${ }^{8}$ Adams and Judd, “2030 Agenda and the SDGs: Indicator Framework, Monitoring and Reporting." 
of the Agenda may follow. For this reason, the UN Statistical Commission emphasizes differences in national realities as well as the international comparability of indicators. However, this generates concerns from developing countries about "dictatorship" of the rich over the indicator framework.

Follow-up and review mechanisms at the global, regional and national levels, as the third element, will ensure the effective implementation of the UN 2030 Agenda. According to the Agenda, each UN member state is encouraged to "conduct regular and inclusive reviews of progress at the national and sub-national levels which are country-led and country-driven." ${ }^{9}$

The follow-up and review process of the UN 2030 Agenda

faces many

challenges from institutional deficiencies.
In building follow-up and review mechanisms, special attention should be paid to two aspects. First, policy coherence within and between four different levels must be promoted; that is, between institutions in different countries that lead the implementation of the Agenda; between development cooperation partners that provide aid for the follow-up and review process; between different aid programs and appropriate channels within development cooperation partners; and between development cooperation partners and recipient governments. Second, a worldwide "data revolution" is urgently needed to facilitate the follow-up and review process. Data revolution, in its broad sense, refers to Internet revolution, big data, and cloud computing. ${ }^{10}$ Under the UN 2030 Agenda framework, however, it is mainly about qualified, timely, and open data. The need for a data revolution actually derives from lessons of the MDGs. "Too often, development efforts have been hampered by a lack of the most basic data about the social and economic circumstances in which people live." Therefore "[w]e must also take advantage of new technologies and

${ }^{9}$ The United Nations, Transforming Our World: The 2030 Agenda for Sustainable Development, p. 36.

${ }^{10}$ For technical discussions about the data revolution, see Tu Zipei, Shuju Zhidian: Dashuju Gemin Lishi Xianshi yu Weilai [The Big Data Revolution: History, Reality and Future] (Beijing: China CITIC Press, 2014); and Tian Limei, "Linked Data: The Upcoming Data Revolution," Journal of Bohai University (Philosophy and Social Science Edition), No. 5, 2014. 
access to open data for all people."11 Targets 17.18 and 17.19 highlight the data revolution. The Chinese government has also promised to help developing countries enhance their statistical capabilities.

The UN 2030 Agenda also aims to "revitalize the Global Partnership for Sustainable Development." In retrospect, a partnership for development was nearly absent before the 21st century. It was not until the World Summit on Sustainable Development held in Johannesburg, South Africa in 2002 that the notion of "partnership for sustainable development" was first put forward. The birth of the concept is largely due to the fact that intergovernmental agreements could hardly deliver development goals, hence the necessity of a substitute partnership from civil society and the private sector. $^{12}$ Therefore, during the implementation of the MDGs, the international community put much focus on the public-private partnership (PPP).

However, during the formulation of the UN 2030 Agenda, the public partnership has come into the spotlight thanks to the growing engagement of emerging powers, which has also brought about the debate between the North and the South over the principle of common but differentiated responsibilities (CBDR). Target 17.17 in the Agenda calls on all countries to "Encourage and promote effective public, public-private and civil society partnerships, building on the experience and resourcing strategies of partnerships," but Indicator 17.17.1 only mentions "Amount of United States dollars committed to public-private and civil society partnerships." "Public partnership" is lost in the indicator, implying that North-South debate over CBDR has yet to come to an end.

Despite all its ambitions, the UN 2030 Agenda will face a number of challenges in its follow-up and review process. Some relatively simple issues like technology transfer, capacity building and data revolution, which are mainly caused by insufficient funding, are being addressed

${ }^{11}$ High-Level Panel of Eminent Persons on the Post-2015 Development Agenda, High Level Panel Bali Communiqué, Bali, Indonesia, March 27, 2013, p. 3.

${ }^{12}$ Jan Kara and Diane Quarless, “Guiding Principles for Partnerships for Sustainable Development ('Type 2 Outcomes') to Be Elaborated by Interested Parties in the Context of the World Summit on Sustainable Development (WSSD)," Paper read at Fourth Summit Preparatory Committee (PREPCOM 4), Bali, Indonesia, May 27-June 7, 2002. 
Table 1. Normalization Governance vs. Indicization Governance.

\begin{tabular}{lll}
\hline & Normalization Governance & Indicization Governance \\
\hline Policy Orientation & Behavior management & Goal management \\
Mobilization & From the top level & From the bottom level \\
Implementation & Collective efforts & Independent contribution \\
Reward/Punishment & Compulsory compliance & Morality, public opinion \\
& and punishment & and social pressure \\
Institutionalization & High & Low \\
Room for Partnership & Limited & Plenty \\
\hline
\end{tabular}

Source: Compiled by author.

by the Addis Ababa Action Agenda, while other issues like mindset differences are more deeply rooted and thus more difficult to settle. Therefore, it is of urgent importance to build a bridge between different policy platforms.

Few people have realized the unique role of a global development agenda in leading global governance efforts. Usually, when talking about global governance, people would first think of institutional arrangements, the focus of which is how different actors should perform their institutional roles, with compliance mechanisms lying at the core. ${ }^{13}$ While this normsetting approach or "normalization governance" emphasizes setting boundaries for behaviors, it often neglects the targets behind those behaviors, listing rather ambiguous goals, such as the 1.5 to $2^{\circ} \mathrm{C}$ increase limit in tackling climate change. In contrast, the UN 2030 Agenda and the MDGs set more measurable goals and targets instead of norms, leaving much more room for individual actors' own deliberations. Such can be seen as an indicator-setting approach, or "indicization governance," so named for its emphasis on various indices of concrete goals.

At present, normalization governance is undoubtedly the more popular form of global governance, yet indicization governance is more evident in global development agendas. Nevertheless, these two approaches are not exclusive of, but complementary to, each other. For normalization governance is deficient in specific goals, while indicization governance lacks necessary norms to guide actors' behaviors (see Table 1).

${ }^{13}$ Abram Chayes and Antonia Handler Chayes, The New Sovereignty: Compliance with International Regulatory Agreements (Cambridge: Harvard University Press 1995). 
As a model of indicization governance, the UN 2030 Agenda is also lacking in effective follow-up mechanisms. Although the Agenda sets forth 62 targets on means of implementation, actual results will largely depend on individual countries' efforts to align those targets with their national strategies. In this sense, the absence of norms may bring new challenges for the Agenda. For instance, individual countries may find 2030 a distant future and thus, out of short-term concerns, tend to direct their limited resources and efforts away from achieving the Agenda. Therefore, the core issue is to establish basic norms for the indicization governance process, to ensure that all countries are committed to aligning their national strategies and policies with the 2030 targets, and that reviews are conducted voluntarily.

Indicization governance requires a standard GTI framework, which gathers all member states under a set of Goals, and mobilizes political willingness and resources for a specific agenda, so that transnational comparison at the global level is possible, especially in ranking and progress tracking according to indicators for Goals and targets. ${ }^{14}$ However, the GTI framework often includes some issues

Following a goal-oriented approach, the UN 2030 Agenda needs a set of basic norms for effective implementation. that cannot be easily measured, such as gender equality and security, so the final indicators may cause policy distortions. For example, policies tend to quantify outcomes, yet quantified social policies and security policies may give rise to perceptive indicators with questionable objectivity. As another example, the indicator-setting process may have completely different policy priorities compared with the 2030 Goals and targets, or even contradict them. Thus, priorities identified by the indicators may be misleading.

It should be noted that indicization governance might result in the separation of many interconnected policy agendas, because these indicators are quantified or simplified. During the indicator-setting process, the IAEGSDGs has tried to cover as many interconnected agendas as possible, for

${ }^{14}$ Hans Krause Hansen and Tony Porter, "What Do Numbers Do in Transnational Governance?" International Political Sociology, Vol. 6, No. 4 (2012), pp. 409-426. 
example, Indicators 1.5.1 and 1.5.2 for Target 1.5 are connected with Targets 2.4, 3.d, 11.5, 13.1, 13.b, 14.2, and 15.3, so they are called "multi-purpose indicators." ${ }^{15}$ Even so, many connections are missing in the indicators.

Although the UN 2030 Agenda has come into force since January 1, 2016, there is still a long way to go to realize the Goals, especially with the lack of follow-up and review mechanisms. Yet up to now, the High-level Political Forum on Sustainable Development (HLPF) has been the only platform set up for that purpose.

Currently, the HLPF plays a central role in overseeing a network of follow-up and review processes at the global level, working coherently with the UN General Assembly, the UN Economic and Social Council (ECOSOC), and other relevant institutions and forums. Meeting every four years under the auspices of the UN General Assembly, the HLPF provides highlevel political guidance on the UN 2030 Agenda and its implementation, identifies progresses and emerging challenges, and mobilizes further actions to accelerate implementation. ${ }^{16}$

The UN Statistical Commission and relevant institutions, especially the Expert Group, provide technical support for the follow-up and review process. According to their respective methodology and data availability, the indicators contained in the current proposal can be grouped into three tiers: Tier 1 refers to the indicators created with sound methodology and ample data; Tier 2 refers to those made with sound methodology but insufficient data; and for Tier 3 indicators, an internationally recognized methodology is yet to be developed. In the future, the priority of the Expert Group will be to create Tier 3 indicators. To make the review more open, all data related to the follow-up and review of the UN 2030 Agenda will be released on the online platform, such as the "Partnerships for SDGs"17 initiated in September 2015. The UN also publishes a Global Sustainable

${ }^{15}$ IEAG-SDGs, "Goal 1: End Poverty in All Its Forms Everywhere," Compilation of Metadata for the Proposed Global Indicators for the Review of the 2030 Agenda for Sustainable Development, Updated on March 3, 2016 (New York: UN, 2016), pp. 11-21.

${ }^{16}$ The first HLPF was held in July 2016, and the next forum will be held in 2019, after which the cycle of forums will be reset to match the quadrennial comprehensive policy review process stipulated in the UN 2030 Agenda.

${ }^{17}$ See the website of Partnerships for SDGs, https://sustainabledevelopment.un.org/ partnerships. 
Development Report annually, aiming to strengthen the science-policy interface at the HLPF.

Outside the HLPF, there is no special institution for facilitating the follow-up and review process of the UN 2030 Agenda, either at the global or regional level. More often, the process depends on the collaboration and coordination between the HLPF and other existing institutions. For the lack of supporting mechanisms, the UN proposes "voluntary national reviews" - "all countries would be expected to regularly carry out reviews at the high-level political forum. Each country could thus consider carrying out up to two voluntary national reviews at the high-level political forum between now and 2030."18 The UN Secretariat also intends to develop an online platform to support and document the reviews of the HLPF.

\section{G20's Role in Fulfilling the UN 2030 Agenda}

With all its strengths and commitments, the G20 can play a leading role in the follow-up and review of the UN 2030 Agenda. For now, the G20 is still an ad hoc crisis management mechanism; its functions and mechanisms are insufficient for promoting long-term sustainable development. Nonetheless, the G20 has demonstrated its political willingness to lead the follow-up and review efforts. For instance, China has pledged to "work out an action plan to implement the 2030 Agenda for Sustainable Development and prioritize the issue of development in macro policy coordination so that the G20 will lead the efforts for common development" during its G20 Presidency in $2016 .{ }^{19}$ To achieve this ambitious goal, the G20 must try to serve as a bridge for the follow-up and review process of the UN 2030 Agenda at the global, regional, and national levels. At present, it is of urgent need to foster a strong and comprehensive internal coordination mechanism within the G20 that is capable of integrating global resources and leading global efforts, so as to facilitate future implementation of the Agenda.

${ }^{18}$ The United Nations, Critical Milestones Towards Coherent, Efficient and Inclusive Followup and Review at the Global Level, A/70/684, January 15, 2016.

${ }^{19}$ Ministry of Foreign Affairs of the People's Republic of China, "Remarks by Foreign Minister Wang Yi at the G20 Session of the Bo'ao Forum for Asia Annual Conference 2016," March 25, 2016, http://www.fmprc.gov.cn/web/wjbz_673089/zyjh_673099/t1350822.shtml. 
The primary task is to strengthen the coordinating capability of the G20$D W G$. Though it is responsible for leading development efforts within the G20, the DWG is indeed a low-ranking body with little power for comprehensive coordination. Thus it is necessary to upgrade the DWG into a Development Working Commission, so that it can connect with traditional development aid institutions - the World Bank's International Development Association (IDA) and the OECD Development Assistance Committee (DAC), for instance- on more or less equal footing, work more closely with partners from emerging economies, and cover broader development agendas. In so doing, it will facilitate the G20's transformation from an ad hoc crisis management mechanism to a long-term global institution of development governance.

Second, the G20 needs to work as a whole to set an example for the rest of the world in implementing the UN 2030 Agenda. As mentioned above, the Agenda lacks behavioral norms and relies on individual countries' voluntary implementation and review. Thus a set of "soft" behavioral norms are needed that best suit the different national contexts and the CBDR principle. This requires a group of model countries to generate "moral" pressure on others. Given its member states' economic size and rich developmental experience, the G20 may be the most qualified candidate for such a model group. To be more specific, the G20-DWG should take the lead in this endeavor, coordinating among different countries and working groups within the G20, as well as integrating all efforts at the working group level, in order to showcase the G20's unity and set a benchmark for implementing the UN 2030 Agenda.

Third, the G20 should facilitate a Global Partnership for sustainable development while advocating for an upgrade of the CBDR principle. Compared with the UN MDGs, the financing demand of the UN 2030 Agenda has risen from "millions to billions," and traditional official development aid (ODA) is no longer sufficient. Thus, the international community needs to "mobilize additional financial resources for developing countries from multiple sources (Target 17.3)," such as national governments, multinational corporations (MNCs), and charity organizations, etc. In terms of international support and finance, Total Official Support for Sustainable Development (TOSSD) is being promoted as a new instrument to mobilize resources. This emerging financial demand calls for the development and cooperation from public partners, public-private partners, and civil society partners. Yet 
considering that public partnership is not reflected in the indicators, the G20 should play an exemplary role in establishing public partnership.

In the meantime, the G20 should promote an upgraded version of the CBDR principle to include three key areas: (1) ensure timely delivery of ODA commitments from developed countries, such as their commitment to contribute 0.7 percent of Gross National Income (GNI) as ODA to developing countries, of which 0.15 to 0.20 percent of GNI to least developed countries (LDCs); (2) encourage emerging powers to set a target of national individual determined contributions (NIDCs) to support SDGs; and (3) help developing countries identify their national targets in terms of domestic resources mobilization.

Upgrading the CBDR principle is both necessary and feasible. On one hand, the principle still lacks concrete implementation mechanisms although it has been recognized by the UN 2030 Agenda. On the other hand, specific ODA targets of developed countries have been identified in the Agenda, while many developing countries, especially African countries, have formulated targets of mobilizing their domestic resources - acquiring 70 to 80 percent of financing from domestic channels. ${ }^{20}$ Thus the G20 is hopeful about substantially facilitating the building of global sustainable development partnership by pushing forward the upgrade and practice of the CBDR principle.

Fourth, the G20 needs to strengthen coordination with the HLPF and other related organizations to enhance the follow-up and review process of the UN 2030 Agenda. Although the HLPF keeps close contact with regional committees, it lacks an efficient intermediary to integrate all efforts. Representing most parts of the globe, the G20 consists of fewer yet more representative member states than the UN, and with stronger executive capability. Therefore, in implementing the UN 2030 Agenda, the G20

Enhancing the function of G20-DWG is the key to successful alignment of the G20 and the UN 2030 Agenda.

20 “Background Note,"Workshop on Agenda 2063 First 10-Year Implementation Plan, Lusaka, Zambia March 2-6, 2015, http://agenda2063.au.int/en/events/workshop-agenda2063-first-10-year-implementation-plan-lusaka-zambia, Annex 3: “Agenda 2063 Financing, Domestic Resource Mobilization and Partnerships." 
can serve as a strong bridge between the UN and different regions, and among institutions at various levels.

As a key G20 institution, the DWG should play an active role in coordinating efforts of G20 members to lay a solid foundation for the HLPF process at the global level, for the preliminary review of G20 countries' domestic progress and international assistance will considerably improve the efficiency of the HLPF. Besides, the G20-DWG should also align the efforts of its member states with those of UN or regional committees. Most G20 members are widely recognized as economic giants or political leaders of their respective regions, so they are in the best position to enhance the follow-up and review process of the UN 2030 Agenda on various regional platforms.

Fifth, the G20 needs to mobilize public awareness of those post-MDG targets and lost-targets, so as to strengthen its central role in fulfilling the UN 2030 Agenda. As mentioned before, post-MDG targets are quite few in the UN 2030 Agenda framework, although many countries, especially some African ones, have failed to achieve multiple MDG targets. For them, the issue of how to realize unfinished MDG targets is still highly relevant. Unfortunately, this has not captured much attention from the international community. Developing countries like China have been emphasizing the importance of post-MDGs, but a lasting mechanism is urgently needed to address the issue at the strategic level. The G20 is an appropriate platform to do so, since its level is neither too high for it to undermine the approved UN 2030 Agenda framework, nor too low to suffer from a lack of mobilizing and executive capacity.

Meanwhile, it is important to note that although the UN 2030 Agenda is all-encompassing, there are lots of targets lost in their translation into indicators, intentionally or unintentionally. For instance, there are 62 targets in the Agenda that explicitly mention international cooperation, yet translated into only 49 indicators. ${ }^{21}$ In other words, 13 international cooperation targets have been lost or replaced in the final document. As a key platform for North-South cooperation, the G20 has a moral obligation to urge the international community, developed countries in particular, to revive those lost targets, so as to ensure balanced implementation of the Agenda.

${ }^{21}$ The United Nations, Transforming Our World: The 2030 Agenda for Sustainable Development. 
Finally, the G20 should actively support the development rights of less developed countries by properly implementing the UN 2030 Agenda. The key is to prevent the traditional North-South relationship, or "donor-recipient" pattern, from arising in any new form. Two issues are of utmost importance: for one, in reviewing various supports and financing for the Agenda, the international community should "respect each country's policy space and leadership to establish and implement policies for poverty eradication and sustainable development" (Target 17.15); for the other, when facilitating the improvement of statistical capacity of developing countries, the international community should take heed of the political risks behind data revolution, especially the countries' data sovereignty and data independence, since data revolution never amounts to "accountability revolution." 22 To truly enhance a country's development capacity, data revolution should focus on statistical capacity building, especially statistical system building, rather than imposing the standards of developed countries upon other countries.

${ }^{22}$ Zhang Chun and Gao Wei, “UN Post-2015 Development Agenda and Global Data Partnership," World Economics and Politics, No. 8 (2015), pp. 99-101. 